\title{
Detection of photoperiod responsive and non-responsive flowering time QTL in barley
}

\author{
Mohammad Sameri, ${ }^{1,3)}$, Mohammad Pourkheirandish'), Guoxiong Chen'), Takuji Tonooka ${ }^{\text {2) }}$ \\ and Takao Komatsuda*1) \\ 1) National Institute of Agrobiological Sciences (NIAS), Kannondai 2-1-2, Tsukuba, Ibaraki 305-8602, Japan \\ 2) National Institute of Crop Science (NICS), Kannondai 2-1-18, Tsukuba, Ibaraki 305-8518, Japan \\ 3) Present address: Department of Plant Biology and Forest Genetics, Swedish University of Agricultural Sciences, Box 7080 , S-750 07 \\ Uppsala, Sweden
}

\begin{abstract}
A QTL analysis was performed to determine the inheritance of flowering time in barley, using a set of recombinant inbred lines developed from a winter-type $\times$ spring-type cross. Two photoperiod responsive loci, Ppd-H1 and Ppd-H2, were detected on chromosome arms 2HS and 1HL respectively. Segregation for eam8 (mapping to the terminus of chromosome arm 1HL) and Eam5 (close to Sgh2 on chromosome arm 5HL) was also observed. These latter two genes functioned under $12 \mathrm{~h}$ to $24 \mathrm{~h}$ photoperiods. In addition, eps $2 S$ and eps $7 \mathrm{~S}$, known to lie on chromosome arms $2 \mathrm{HS}$ and 7HS respectively, were detected. A new QTL for flowering time, qDHE.ak-1HS, was mapped $23 \mathrm{cM}$ from the terminus of chromosome 1HS, and appears to be expressed under extremely short day lengths.
\end{abstract}

Key Words: Earliness per se, photoperiod response, spring growth habit, flowering time, flowering date.

\section{Introduction}

The control of flowering time is central for the reproductive success of plants and has a major impact on grain yield (Cockram et al. 2007, Sameri et al. 2006, Sameri and Komatsuda 2007). Flowering is often restricted to a particular time of year. In barley, three classes of genes control flowering time: those responsive to photoperiod (day length), those responsive to vernalization, and earliness per se. All three classes influence the transition from vegetative to reproductive growth (Laurie et al. 1995, Takahashi and Yasuda 1970).

Particular photoperiod responsiveness has been selected for in many crops to adapt the plants to specific environments and farming practices (Turner et al. 2005). Barley is a long-day photoperiod plant, so that its transition to reproductive growth is significantly delayed when grown under short day conditions (Laurie 1997, Stockinger et al. 2007). Extremely early flowering winter-type cultivars can be damaged by late frost, whereas in the Far East region, late flowering ones typically yield poorly and produce poor quality grain due to seasonal rainfall patterns. Photoperiod also plays an important role in determining winter hardiness (Hayes et al. 1997, Szücs et al. 2006, Takahashi and Yasuda 1970). The photoperiod response gene Ppd-H1, located on chromosome arm $2 \mathrm{HS}$, regulates flowering time under long

Communicated by Donghe $\mathrm{Xu}$

Received August 31, 2010. Accepted March 29, 2011.

*Corresponding author (e-mail: takao@affrc.go.jp) days, while $\mathrm{Ppd}-\mathrm{H} 2$ on chromosome arm 1HL functions only under short days (Laurie et al. 1995). Ppd-H1 encodes a pseudo-response regulator (PRR) (Turner et al. 2005), which is different from the major photoperiod response genes $H d l$ and $H d 3 a$ in rice (Kojima et al. 2002, Yano et al. 2000). Ppd-H2 encodes HvFT3, an FT-like gene (Faure et al. 2007, Kikuchi et al. 2009).

Earliness per se affects flowering time independently of day length and vernalization. Several recessive mutants generate an early flowering phenotype, including ea7 (eam7), eac (eam9), ea $a_{k}(e a m 8)$ and $e a_{s p}$ (eam10) (Börner et al. 2002, Franckowiak et al. 1997, Lundqvist et al. 1997, Takahashi and Yasuda 1970, Yasuda et al. 1965). None of the genes responsible for this phenotype has yet been isolated, although some candidates have been suggested (Kikuchi and Handa 2009). Barley germplasm can be broadly divided into winter, facultative, and spring types (Mahfoozi et al. 2001, Szücs et al. 2006). Three epistatic genes Vrn-H1 (Sgh2), $\mathrm{Vrn}-\mathrm{H} 2$ (sgh1), and Vrn-H3 (Sgh3), located on chromosomes $5 \mathrm{H}, 4 \mathrm{H}$ and $7 \mathrm{H}$, respectively, are responsible for the spring growth habit (Sameri and Komatsuda 2004, Takahashi and Yasuda 1956). These genes are homologues of AP1, ZCCT and FT, respectively (Yan et al. 2003, 2004, 2006).

Although many genetic studies of flowering time have been performed-leading to the recognition of the major genes responsible for photoperiod sensitivity, earliness per se and the vernalization response (Cockram et al. 2007, Kikuchi and Handa 2009) - the genetic resources analysed in these studies have mostly excluded oriental barley 
germplasm. Thus the objective of the current study was genetically to characterize the determination of flowering time in barley, with a special emphasis on photoperiod responsiveness and earliness per se.

\section{Materials and Methods}

\section{Mapping population}

A set of 99 recombinant inbred lines (RILs) at the $F_{12}$ generation were bred from the cross Azumamugi (wintertype) $\times$ Kanto Nakate Gold (spring-type) by single seed descent. Azumamugi is a Japanese cultivar with characteristics of typical oriental-type cultivars (Sameri et al. 2006).

\section{Flowering under controlled photoperiods}

The RILs (two plants per RIL) and their parental cultivars were grown in a randomized complete block design as replicated sets in two identical growth chambers (Koito Kogyo, Tokyo). The temperature for the first two weeks post germination was $20^{\circ} \mathrm{C}$ and the daylength set to $8 \mathrm{~h}$. Vernalization was achieved by maintaining the seedlings for six weeks at $4^{\circ} \mathrm{C}$ under an $8 \mathrm{~h}$ photoperiod. After vernalization, the temperature was raised to $20^{\circ} \mathrm{C}$, and five different photoperiod treatments $(10 \mathrm{~h}, 12 \mathrm{~h}, 14 \mathrm{~h}, 16 \mathrm{~h}$ and $24 \mathrm{~h}$ : respectively, Ppd-10 h, Ppd-12 h, Ppd-14 h, Ppd-16 h and Ppd-24 h) were examined. The main effect of the photoperiod treatments (Ppd-MEP) was defined for each line by subtracting the number of days from sowing to flowering in the Ppd-24 h treatment from the number of days from sowing to flowering in the Ppd-12 h treatment. Flowering was defined by the awn emergence from the flag leaves.

\section{Flowering in the field}

Three field experiments were conducted. In the first, vernalized RIL seedlings were transplanted in early April (Ppd$\mathrm{SV})$; in the second, the RILs were sown without vernalization in early April (Ppd-SNV); and in the third, the RILs were sown in mid October (Ppd-autumn), as for a conventional winter-type crop. The photoperiod was $11 \mathrm{~h} 12 \mathrm{~min}$ in mid October, $9 \mathrm{~h} 32 \mathrm{~min}$ in late December (the winter solstice), $12 \mathrm{~h} 47 \mathrm{~min}$ in early April, $14 \mathrm{~h} 39 \mathrm{~min}$ in late June (the summer solstice) and $14 \mathrm{~h} 18 \mathrm{~min}$ in mid July, and the mean daily temperature ranged from $4.3^{\circ} \mathrm{C}$ to $34.2^{\circ} \mathrm{C}$, with an overall mean of $18.0^{\circ} \mathrm{C}$. Rows of each RIL contained 10 plants, and days to flowering indicated the number of days from sowing to the time when in $50 \%$ of the ears the base had emerged from the flag leaf sheath.

\section{QTL detection}

The linkage map of Sameri et al. (2009) was used for the QTL analysis. This map is based on that of Mano and Komatsuda (2002), with the addition of 37 microsatellite loci. Composite interval mapping (CIM) was performed using Windows QTL Cartographer v2.0 (Wang et al. 2004). The LOD threshold for the presence of a QTL was estimated from a 1,000 permutation test.

\section{Results}

Photoperiod sensitive flowering time QTL

Days to flowering varied widely among the RILs grown in the growth chamber (Fig. 1). Two major genes governing flowering time were located - one on chromosome arm $1 \mathrm{HL}$ and the other on $2 \mathrm{HS}$, corresponding to $\mathrm{Ppd}-\mathrm{H} 2$ and $\mathrm{Ppd}-\mathrm{H1}$, respectively (Table 1). Both $\mathrm{Ppd}-\mathrm{H1}$ and $\mathrm{Ppd}-\mathrm{H} 2$ were expressed exclusively in the Ppd-12 h treatment. The Azumamugi $\mathrm{Ppd}-\mathrm{H} 2$ allele delayed flowering by 17.6 days compared to the Kanto Nakate Gold allele, while the Azumamugi Ppd-H1 allele accelerated it by 19.1 days (Table 1). The MEP parameter detected only Ppd-H2 and $P p d-H 1$, with the map location of $P p d-H 2$ placed $\sim 10 \mathrm{cM}$ distal to that detected under the Ppd- $12 \mathrm{~h}$ treatment. A flowering time QTL was detected under the Ppd-10 h treatment, mapping $23 \mathrm{cM}$ from the terminus of chromosome arm 1HS (hereafter qDHE.ak-1HS), and was flanked by Bmac0213 and e12m22.8 (Table 1). The Azumamugi $q$ DHE.ak-1HS allele accelerated flowering by 34.4 days. This QTL was not detected under any of the other photoperiod treatments.

\section{Photoperiod insensitive flowering time QTL}

Two QTL were detected on chromosome arms 1HL and 5HL under the Ppd-12 h, $-14 \mathrm{~h},-16 \mathrm{~h}$ and $-24 \mathrm{~h}$ treatments, suggesting that their expression was relatively insensitive to photoperiod (Table 1). The location of the QTL corresponded to, respectively, eam8 (formerly $e a_{k}$, Franckowiak et al. 1997, Yasuda et al. 1965) and Eam5 (Franckowiak 2002). The two loci were mapped in classical linkage maps in these studies but they were mapped in molecular linkage maps in this study. The two genes were detectable in varying photoperiod (Table 1) indicating their expression is photoperiod insensitive. The additive effect of the Azumamugi eam 8 allele delayed flowering by 5.9-23.1 days, whereas that of the Azumamugi Eam5 allele accelerated it by 2.8-22 days. These effects were also noticeable in the Ppd-SV and Ppdautumn field experiments, although the additive effects were smaller than those detected in the growth chamber experiments. Neither eam 8 nor Eam5 was detectable in the Ppd$10 \mathrm{~h}$ treatment, suggesting that there is a minimum photoperiod necessary for their expression-in other words, the genes are sensitive to photoperiod to some degree.

eps $2 S$ and eps $7 S$ have also been described as earliness per se genes (Laurie et al. 1995), but here they were only expressed in the Ppd-24 h treatment. Thus, they only function under photoperiods which occur only at the poles in mid summer. This implies that the two genes are in fact sensitive to photoperiod. The additive effect of both eps $2 S$ and eps $7 S$ was small (2.1 and 1.7 days, respectively).

\section{Flowering time genes detected under field conditions}

The Ppd-SV experiment allowed the detection of four loci: eam8, eps $2 S$, Eam5 and qDHE.ak-7H, located on chromosome arms $1 \mathrm{HL}, 2 \mathrm{HS}, 5 \mathrm{HL}$ and $7 \mathrm{H}$, respectively 

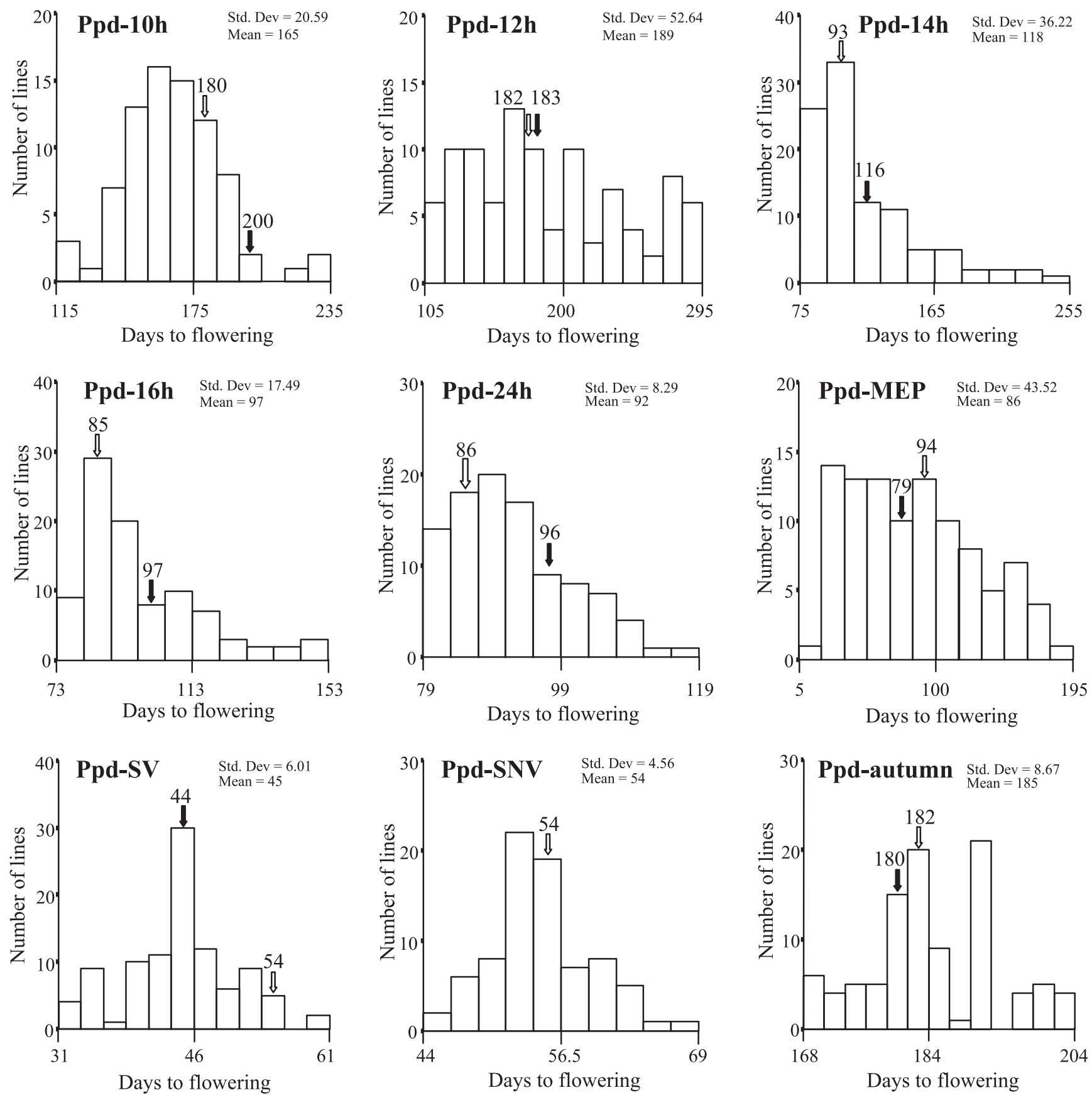

Fig. 1. Frequency distribution of the number of days to flowering in response to variation in the photoperiod in the Azumamugi/Kanto Nakate Gold RILs. The mean performance over two plants and two growth chambers is given for each RIL. The performance of Azumamugi and Kanto Nakate Gold is indicated by a black and a white arrow, respectively. After vernalization, the temperature was raised to $20^{\circ} \mathrm{C}$, and five different photoperiod treatments ( 10 h, 12 h, 14 h, 16 h and 24 h: respectively, Ppd-10 h, Ppd-12 h, Ppd-14 h, Ppd-16 h and Ppd-24 h) were examined. In the field experiments, vernalized RIL seedlings were transplanted in early April (Ppd-SV); non-vernalized RILs were sown in early April (Ppd-SNV); and the other RILs were sown in mid October (Ppd-autumn),

(Table 1). Arm location of qDHE.ak-7H is unknown. qDHE.ak-7H was expressed in the Ppd-SV treatment, and thus is responsive to the lengthening of the photoperiod as spring advanced. The same QTL was also detected in a spring sowing of non-vernalized barley (Sameri and Komatsuda 2004), which indicates that its action is independent of vernalization. In the Ppd-SNV experiment, the flow- ering time of the 20 winter habit RILs was greatly delayed, and these were therefore eliminated from the QTL analysis. The analysis detected the presence of two flowering time genes, one corresponding to sghl on chromosome arm 4HL, and the other to Eam5 on chromosome arm 5HL. RILs carrying the Azumamugi allele at each locus accelerated flowering (Table 1). In the Ppd-autumn experiment, one QTL, 
Table 1. Flowering time QTL detected in the Azumamugi/Kanto Nakate Gold RILs

\begin{tabular}{|c|c|c|c|c|c|c|c|}
\hline Trait & Chr. & Flanking markers & Pos. cM & LOD & $\mathrm{AE}^{a}$ & $\mathrm{PVE}^{b}$ & Locus \\
\hline Ppd-10 h & $1 \mathrm{HS}$ & Bmac0213-e12m22.8 & 23.31 & 4.42 & -34.46 & 0.198 & qDHE.ak-1HS \\
\hline \multirow[t]{4}{*}{ Ppd-12 h } & $1 \mathrm{HL}$ & $e 02 \mathrm{~m} 18.4-e 06 \mathrm{~m} 18.10$ & 101.31 & 4.45 & 17.68 & 0.109 & Ppd-H2 \\
\hline & $1 \mathrm{HL}$ & $A B C 261-A B G 055$ & 151.91 & 6.18 & 22.27 & 0.165 & eam8 (eak) \\
\hline & $2 \mathrm{HS}$ & e08m18.7-ABG602 & 39.51 & 3.40 & -19.11 & 0.121 & Ppd-H1 \\
\hline & $5 \mathrm{HL}$ & $e 07 m 25.3-e 12 m 19.9 .1$ & 125.81 & 6.03 & -22.03 & 0.168 & Eam5 \\
\hline \multirow[t]{2}{*}{ Ppd-14 h } & $1 \mathrm{HL}$ & $A B C 261-A B G 055$ & 151.91 & 15.60 & 23.16 & 0.392 & eam8 (eak) \\
\hline & $5 \mathrm{HL}$ & $e 07 m 25.3-e 12 m 19.9 .1$ & 129.81 & 8.13 & -15.23 & 0.169 & Eam5 \\
\hline \multirow[t]{2}{*}{ Ppd-16 h } & $1 \mathrm{HL}$ & $A B C 261-A B G 055$ & 151.91 & 18.88 & 12.59 & 0.458 & eam8 (eak) \\
\hline & $5 \mathrm{HL}$ & $e 07 m 25.3-e 12 m 19.9 .1$ & 131.81 & 7.76 & -6.73 & 0.136 & Eam5 \\
\hline \multirow[t]{4}{*}{ Ppd-24 h } & $1 \mathrm{HL}$ & $A B C 261-A B G 055$ & 151.91 & 20.00 & 5.94 & 0.473 & eam8 (eak) \\
\hline & $2 \mathrm{HS}$ & ЕВтас0607-EВтас0623 & 48.41 & 4.16 & -2.18 & 0.064 & eps $2 S$ \\
\hline & $5 \mathrm{HL}$ & $e 07 m 25.3-e 12 m 19.9 .1$ & 129.81 & 6.17 & -2.88 & 0.115 & Eam5 \\
\hline & 7HS & $A B G 616-e 15 m 31.6$ & 28.41 & 2.93 & -1.77 & 0.044 & eps $7 S$ \\
\hline \multirow[t]{2}{*}{ Ppd-MEP ${ }^{c}$} & $1 \mathrm{HL}$ & $e 02 \mathrm{~m} 18.4-e 06 \mathrm{~m} 18.10$ & 111.31 & 3.79 & 25.63 & 0.337 & $\mathrm{Ppd}-\mathrm{H} 2$ \\
\hline & $2 \mathrm{HS}$ & $e 08 m 18.7-A B G 602$ & 35.51 & 3.45 & -18.52 & 0.176 & Ppd-H1 \\
\hline \multirow[t]{4}{*}{ Ppd-SV } & $1 \mathrm{HL}$ & $A B C 261-A B G 055$ & 151.91 & 9.10 & 2.52 & 0.167 & eam8 (eak) \\
\hline & $2 \mathrm{HS}$ & e13m23.6-e13m31.7.1 & 52.61 & 11.97 & -2.89 & 0.226 & eps $2 S$ \\
\hline & $5 \mathrm{HL}$ & $e 07 m 25.3-e 12 m 19.9 .1$ & 127.81 & 14.00 & -3.60 & 0.347 & Eam5 \\
\hline & $7 \mathrm{H}$ & el1m17.10.2-e12m19.10.3 & 100.61 & 3.55 & 1.56 & 0.063 & qDHE.ak-7H \\
\hline \multirow[t]{2}{*}{ Ppd-SNV } & $4 \mathrm{HL}$ & $e 12 m 19.10 .2-e 04 m 32.8$ & 96.21 & 3.77 & -7.05 & 0.096 & $\operatorname{sgh} 1$ \\
\hline & $5 \mathrm{HL}$ & Hvlox-e07m25.3 & 123.51 & 10.60 & -12.02 & 0.281 & Eam5 \\
\hline \multirow[t]{4}{*}{ Ppd-autumn } & $1 \mathrm{HL}$ & $M W G 2077-e 02 m 18.4$ & 97.81 & 5.33 & 3.30 & 0.126 & Ppd-H2 \\
\hline & $1 \mathrm{HL}$ & $A B C 261-A B G 055$ & 149.91 & 4.92 & 3.00 & 0.117 & eam8 (eak) \\
\hline & $2 \mathrm{HS}$ & e13m23.6-e13m31.7.1 & 52.61 & 8.39 & -3.68 & 0.176 & eps $2 S$ \\
\hline & $5 \mathrm{HL}$ & $e 07 m 25.3-e 12 m 19.9 .1$ & 127.81 & 13.33 & -4.93 & 0.317 & Eam5 \\
\hline
\end{tabular}

${ }^{a}$ The additive effect of the Azumamugi allele.

${ }^{b}$ The proportion of phenotypic variance explained by the detected QTL.

${ }^{c}$ Ppd-MEP $($ main effect of photoperiod $)=($ Ppd-12 h $)-($ Ppd-24 h $)$.

corresponding to $\mathrm{Ppd}-\mathrm{H} 2$, was detected on chromosome arm 1HL, close to e02m18.4 (Table 1).

\section{Discussion}

Photoperiod sensitive genes

Two QTL affecting photoperiod response in barley were detected in the growth chamber experiments. One mapped in the same region as $\mathrm{Ppd}-\mathrm{H} 2$, according to the barley consensus map (http://www.graingenes.org), and was only expressed under a $12 \mathrm{~h}$ photoperiod. The spring-type parent Kanto Nakate Gold carries a photoperiod-responsive Ppd$H 2$ allele, which accelerated flowering under short photoperiods. The segregation of a flowering time QTL in the Apex $\times$ Prisma mapping population (Yin et al. 2005), which also maps to this region, probably also corresponds to Ppd$H 2$. We also detected a photoperiod sensitive QTL on chromosome arm $2 \mathrm{HS}$, since it was only detectable under the Ppd-12 h and MEP treatments (Table 1). At this locus the Azumamugi allele accelerated flowering by 18 days. The location and action of this QTL corresponds to Ppd-H1. Indeed, a study by Turner et al. (2005) demonstrated that cultivars carrying the dominant $P p d-H 1$ allele flower 20 days earlier than cultivars carrying the recessive $p p d-H 1$ allele, further supporting our conclusion. This study detected both Ppd-H1 and Ppd-H2 in the $12 \mathrm{~h}$ treatment (Table 1). In general, $P p d-H 1$ is a long-day regulator and $P p d-H 2$ is a shortday regulator for flowering. Kanto Nakate Gold allele for Ppd-H1 delayed flowering at only the $12 \mathrm{~h}$ condition, and it did not function in the longer day-length condition. The results suggest that the Kanto Nakate Gold allele was different from the alleles of northern European spring cultivars. The $q$ DHE.ak-1HS locus was detected in an extremely short daylength condition, probably not occuring in nature, and was not detected under any of the other photoperiod treatments. Effects of $q D H E$.ak-1HS were as large as 30 days difference of flowering. However the biological function of the $q D H E . a k-1 H S$ locus can not be discussed until the gene products encoded by the gene are clarified. This QTL requires further study to understand its biological roles. Nearisogenic lines for this gene may allow further characterization of the genes as for the case of other agronomic traits (Sameri et al. 2009).

\section{Earliness per se genes}

We have shown earlier (Sameri et al. 2006, 2009) that the 
QTL lying close to $A B C 261$ on chromosome arm 1HL is likely to be eam8, as identified by Takahashi and Yasuda (1970) (Table 1). This locus here was one of the major determinants of flowering time under a wide range of photoperiod treatments. Yin et al. (2005) have similarly mapped a flowering time QTL to the terminus of chromosome arm $1 \mathrm{HL}$ in their Apex $\times$ Prisma mapping population. A further major QTL insensitive to photoperiod, believed to be Eam5, mapped close to $\mathrm{Sgh} 2(\mathrm{Vrn}-\mathrm{H} 1)$ locus in all of the treatments except Ppd-10 h. As this QTL was also detected under natural day length conditions from a spring sowing (Sameri and Komatsuda 2004), the detection of this locus may have been thanks to the pleiotropic effect of $\mathrm{Sgh} 2$. Yasuda and Okinaga (1977) have shown that the effect of Sgh2 on flowering time depends on the genetic background of the cultivar. In Triticum monococcum, the vernalization gene Vrnl encodes an APETALA1 transcription factor, with a number of other genes implicated in the control of flowering physically located close to it (Yan et al. 2003). Thus it is possible that Eam5, rather than being a homologue of $S g h 2$, is related to one of these linked genes. Some support for this notion comes from the observation that the Azumamugi Eam5 allele accelerates early flowering, while the Azumamugi Sgh2 allele delays it in the absence of vernalization. At the QTL described by Cuesta-Marcos et al. (2008), the winter-type allele delayed flowering, indicating that their QTL corresponded to $S g h 2$ rather than to Eam5. This study clearly indicated the major effects of the two earliness per se genes over different day-length conditions, and near-isogenic lines for these genes (Sameri et al. 2009) may allow a fine mapping and further characterization of the genes.

The eps $2 S$ gene on chromosome arm 2HS was detected in the Ppd-24 h, the Ppd-SV and the Ppd-autumn treatments (Table 1). As Laurie et al. (1995) detected this locus under $10 \mathrm{~h}, 13 \mathrm{~h}$ and $16 \mathrm{~h}$ photoperiod treatments after vernalization and autumn sowing, it has been considered as being photoperiod neutral and classified among the earliness per se genes. Here, however, eps $2 S$ was detected in the $24 \mathrm{~h}$ photoperiod treatment in addition to the field-grown vernalized material, suggesting that eps $2 S$ is not necessarily photoperiod insensitive. An alternative explanation could be that eps $2 S$ is photoperiod insensitive, but that its effect is considerably weaker than that of either eam8 or Eam 5 and was therefore not detected in our QTL analysis. The chromosome arm 7HS locus, likely to be eps $7 S$, behaves similarly to eps $2 S$ in terms of its photoperiod insensitivity. The map position defined by Laurie et al. (1995) for eps $7 S$ is consistent with the present one. The outcome of the Ppd- $24 \mathrm{~h}$ experiment confirmed that this locus determines earliness per se. However, as for eps $2 S$, eps $7 S$ is not necessarily photoperiod insensitive - either it is photoperiod sensitive to some extent, or its effect is much weaker than that of either eam 8 or Eam5.

\section{Vernalization response genes}

A recessive spring growth habit gene, sghl (vrn-H2), was identified by Takahashi and Yasuda (1956) and located on chromosome 4H (Laurie et al. 1995, Takahashi et al. 1958, Yan et al. 2004). Sameri and Komatsuda (2004) found a close linkage between sgh1 and $e 04 m 32.8$. Here, the PpdSNV treatment detected a QTL lying close to vrn-H2. The transcription of the likely wheat homologue of $\mathrm{vrn}-\mathrm{H} 2$ is down-regulated by vernalization (Yan et al. 2004), so it is understandable that the QTL was not recognized in experiments where the plants had been vernalized.

\section{Acknowledgements}

The authors thank Rie Kikuchi for valuable comments on the manuscript and Kayoko Sameri for her excellent technical support. This research was financially supported by the Ministry of Agriculture, Forestry, and Fisheries of Japan (Genomics for Agricultural Innovation grant no. TRC1004).

\section{Literature Cited}

Börner,A., G.H.Buck-Sorlin, P.M.Hayes, S.Malyshev and V.Korzun (2002) Molecular mapping of major genes and quantitative trait loci determining flowering time in response to photoperiod in barley. Plant Breed. 121: 129-132.

Cockram,J., H.Jones, F.J.Leigh, D.O'Sullivan, W.Powell, D.A.Laurie and A.J.Greenland (2007) Control of flowering time in temperature cereals: genes, domestication, and sustainable productivity. J. Exp. Bot. 58: 1231-1244.

Cuesta-Marcos, A., E. Igartua， F.J.Ciudad，P.Codesal，J.R. Russell, J.L.Molina-Cano, M.Moralejo, P.Szücs, M.P.Gracia, J.M.Lasa et al. (2008) Heading date QTL in a spring $\times$ winter barley cross evaluated in Mediterranean environments. Mol. Breed. 21: 455-471.

Faure,S., J.Higgins, A.Turner and D.A.Laurie (2007) The FLOWERING LOCUS T-Like gene family in barley (Hordeum vulgare). Genetics 176: 599-609.

Franckowiak,J.D., U.Lundqvist, T.Konishi and L.W.Gallagher (1997) BGS 214, early maturity 8, eam8. Barley Genet. Newsl. 26: 213215 .

Franckowiak,J.D. (2002) BGS 348, early maturity 5, Eam5. Barley Genet. Newsl. 32: 109.

Hayes, P.M., F.Q.Chen, A.Corey, A.Pan, T.H.H.Chen, E.Baird, W.Powell, W.Thomas, R.Waugh, Z.Bedo et al. (1997) The Dicktoo $X$ Morex population: a model for dissecting components of winter hardiness in barley. In: Li,P.H. and T.H.H.Chen (eds.) Plant Cold Hardiness, Plenum Press, New York, pp. 77-87.

Kikuchi,R. and H.Handa (2009) Photoperiodic control of flowering in barley. Breed. Sci. 59: 546-552.

Kikuchi,R., H.Kawahigashi, T.Ando, T.Tonooka and H.Handa (2009) Molecular and functional characterization of PEBP genes in barley reveal the diversification of their roles in flowering. Plant Physiol. 149: 1341-1353.

Kojima,S., Y.Takahashi, Y.Kobayashi, L.Monna, T.Sasaki, T.Araki, M.Yano (2002) Hd3a, a rice ortholog of the Arabidopsis FT gene, promotes transition to flowering downstream of $H d l$ under shortday conditions. Plant and Cell Physiol. 43: 1096-1105.

Laurie, D.A. (1997) Comparative genetics of flowering time. Plant Mol. Biol. 35: 167-177.

Laurie,D.A., N.Pratchett, J.H.Bezant and J.W.Snape (1995) RFLP 
mapping of five major genes and eight quantitative trait loci controlling flowering time in a winter $\times$ spring barley (Hordeum vulgare L.) cross. Genome 38: 575-585.

Lundqvist, U., J.D.Franckowiak and T.Konishi (1997) New and revised descriptions of barley genes. Barley Genet. Newsl. 26: 22516.

Mahfoozi,S., A.E.Limin and D.B.Fowler (2001) Influence of vernalization and photoperiod responses on cold hardiness in winter cereals. Crop Sci. 41: 1006-1011.

Mano,Y. and T.Komatsuda (2002) Identification of QTLs controlling tissue-culture traits in barley (Hordeum vulgare L.). Theor. Appl. Genet. 105: 708-715.

Sameri,M. and T.Komatsuda (2004) Identification of quantitative trait loci (QTLs) controlling heading time in the population generated from a cross between oriental and occidental barley cultivars (Hordeum vulgare L.). Breed. Sci. 54: 327-332.

Sameri,M., K.Takeda and T.Komatsuda (2006) Quantitative trait loci controlling agronomic traits in recombinant inbred lines from a cross between oriental- and occidental-type barley cultivars. Breed. Sci. 56: 243-252.

Sameri,M. and T.Komatsuda (2007) Localization of quantitative trait loci for yield components in a cross oriental $\times$ occidental barley cultivars (Hordeum vulgare L.). Japan Agric. Res. Quart. 41: 195199.

Sameri, M., S. Nakamura, S.K.Nair, K. Takeda and T. Komatsuda (2009) A quantitative trait locus for reduced culm internode length in barley segregates as a Mendelian gene. Theor. Appl. Genet. 118: 643-652.

Stockinger,E.J., J.S.Skinner, K.G.Gardner, E.Francia and N.Pecchioni (2007) Expression levels of barley Cbf genes at the Frost resistance-H2 locus are dependent upon alleles at $\mathrm{Fr}-\mathrm{H1}$ and Fr-H2. Plant J. 51: 308-321.

Szűcs,P., I.Karsai, J.von Zitzewitz, K.Mészáros, L.L.Cooper, Y.Q.Gu, T.H.Chen, P.M.Hayes and J.S.Skinner (2006) Positional relationship between photoperiod response QTL and photoreceptor and vernalization genes in barley. Theor. Appl. Genet. 112: 12771285 .

Takahashi,R. and S. Yasuda (1956) Genetic studies of spring and winter habit of growth habit in barley. Ber. Ohara Inst. Iandwirtsch.
Biol. Okayama Univ. 10: 245-308.

Takahashi, R., J.Hayashi and S. Yasuda (1958) Four genes in linkage which are inherited independently of the markers in the known seven linkage groups in barley. Nogaku Kenkyu 45: 49-58.

Takahashi, R. and S.Yasuda (1970) Genetics of earliness and growth habit in barley. Barley Genetics 2: 388-408.

Turner,A., J.Beales, S.Faure, R.P.Dunford and D.A.Laurie (2005) The pseudo-response regulator $\mathrm{Ppd}-\mathrm{H} 1$ provides adaptation to photoperiod in barley. Science 310: 1031-1034.

Wang, S., C.J.Basten, P.Gaffney and Z.B.Zeng (2004) Windows QTL Cartographer version2.0. Statistical Genetics, North Carolina State University, Raleigh, North Carolina, USA.

Yan,L.L., A.Loukoianov, G.Tranquilli, M.Helguera, T.Fahima and J.Dubcovsky (2003) Positional cloning of the wheat vernalization gene VRN1. Proc. Natl. Acad. Sci. USA 100: 6263-6268.

Yan,L.L., A.Loukoianov, A.Blechl, G. Tranquilli, W.Ramakrishna, P.San Miguel, J.L.Bennetzen, V.Echenique and J.Dubcovsky (2004) The wheat VRN2 gene is a flowering repressor downregulated by vernalization. Science 303: 1640-1644.

Yan, L.L., D.Fu, C.Li, A. Vlechl, G. Tranquilli, M.Bonafede, A. Sanchez, M.Valarik, S. Yasuda and J.Dubcovsky (2006) The wheat and barley vernalization gene VRN3 is an orthologue of FT. Proc. Natl. Acad. Sci. USA 103: 19581-19586.

Yano, M., Y.Katayose, M.Ashikari, U. Yamanouchi, L. Monna, T. Fuse, T.Baba, K. Yamamoto, Y.Umehara, Y. Nagamura et al. (2000) $H d l$ a major photoperiod sensitivity quantitative trait locus in rice is closely related to the Arabidopsis flowering time gene CONSTANS. The Plant Cell 12: 2473-2483.

Yasuda,S., T.Konishi and H.Shimoyama (1965) Varietal difference in yellowing of barleys under a certain controlled condition of temperature and photoperiod, and its mode of inheritance. Nogaku Kenkyu 51: 53-62.

Yasuda,S. and Y.Okinaga (1977) Physiology and genetics of ear emergence in barley and wheat. X. Effects of four genes for spring habit on yield and yield components in barley. Nogaku Kenkyu 56: 143-154.

Yin,X., P.C.Struik, F.A.vanEeuwijk, P.Stam and J.Tang (2005) QTL analysis and QTL-based prediction of flowering phenology in recombinant inbred lines of barley. J. Exp. Bot. 56: 967-976. 